Session 1566

\title{
Development of an Extended Campus Mechanical Engineering Program
}

\author{
Vincent R. Capece, William E. Murphy, G.T. Lineberry, and Bonita Lykins \\ University of Kentucky
}

\begin{abstract}
The University of Kentucky College of Engineering is currently in the process of establishing mechanical and chemical engineering programs in the Purchase Area region of western Kentucky. These extended campus programs being developed are unique because they are located on a community college campus 255 miles from the main Lexington campus, and they are the direct responsibility of the Lexington campus College of Engineering dean. The motivation for developing these programs was to provide engineering graduates and further engineering educational opportunities for local industries in the area. The programs were initiated after Kentucky's Council on Higher Education passed a resolution, based on a needs assessment, directing three educational institutions (University of Kentucky, Murray State University, and Paducah Community College) to cooperate in establishing ABET-accredited undergraduate programs in mechanical and chemical engineering in the western Kentucky region, with the University of Kentucky designated as the degree-granting institution. This paper will provide an overview of the development of the extended campus program in mechanical engineering, including a description of the extended campus concept, the role of distance learning, comparative programs state-wide and nationally, and efforts toward ABET accreditation.
\end{abstract}

\section{Introduction}

In November 1995 Kentucky's Council on Higher Education passed a resolution directing three educational institutions to cooperate in establishing ABET-accredited undergraduate programs in mechanical and chemical engineering in the western Kentucky region. The University of Kentucky (UK) was designated to be the degree-granting institution, with Murray State University (MuSU) and the University of Kentucky responsible for the upper division courses, and the University of Kentucky, Murray State University, and Paducah Community College (PCC) responsible for the lower division instruction. MuSU is a western Kentucky university with an accredited engineering technology program. The locations of these institutions are illustrated in Figure 1, which presents a map of the Commonwealth of Kentucky.

The genesis of the resolution was based upon employers in the Purchase Area region, also illustrated in Figure 1, reporting difficulties in recruiting and retaining engineers. It was felt that one cause for these difficulties was inadequate opportunities for employees to pursue undergraduate, graduate, and continuing engineering education in the region. Hence, the proposed programs are designed to prepare students for the local employment market, which is strongly linked to chemical, 
manufacturing, and separation industries. The largest industry in this nine-county region is a uranium enrichment plant. Overall there are 35 companies in this region employing between 100 and 2000 employees. The population for the nine counties totals approximately 200,000.

The resolution was passed based upon recommendations from a needs assessment conducted by a management and consulting firm ${ }^{1}$ in the late summer of 1995. This assessment indicated that the annual demand for engineers in the region could be between 20-60 additional engineering graduates per year over the number currently available.

The Kentucky General Assembly adopted the resolution and provided \$1.5M in funding to initiate and administer the extended campus program. The engineering programs are located on the Paducah Community College campus, which is 255 miles from the main University of Kentucky campus in Lexington. To house the engineering program, a new engineering building was constructed on the Paducah Community College campus with $\$ 8.3 \mathrm{M}$ of locally generated funding. The program started in the summer of 1997 with 5 students (4 mechanical engineering). In the fall of 1999, there were 89 engineering students in the program (55 students enrolled in mechanical engineering with an additional 12 in sophomore prerequisite curriculum).

\section{Program Description}

\section{A. Organization}

The Council on Higher Education (CHE) Resolution included an explicit directive to UK, MuSU, and PCC to cooperate in developing two new undergraduate engineering programs, one in chemical and one in mechanical engineering. This paper will concentrate on the mechanical engineering program. In late winter of 1996, the dean of the UK College of Engineering, the dean of the MuSU College of Industry and Technology (who is also the MuSU director of the Engineering Institute) and the president of Paducah Community College, jointly assembled a team of approximately 20 faculty and staff to develop these two new baccalaureate programs. This group included a representative from the CHE and an ABET-knowledgeable EAC member, the latter to provide advice regarding program development and accreditation. Some of the pertinent issues addressed were tuition collection and financial aid matters, commonality in course objectives and expected student outcomes, equipment needs, computers and related infrastructure needs, recruitment and admission details, transfer opportunities, provision of student services, quality control issues, library acquisitions, and use of distance learning technologies.

Organizationally, the UK dean of the College of Engineering has ultimate responsibility for the extended campus engineering programs in Paducah. The director of the extended campus engineering programs reports to the dean and interfaces regularly with the associate dean for extended campus programs, who serves as a liaison with the Lexington campus faculty and administration. The director is responsible for routine daily administration of the Paducah-based programs, with department chairs in chemical and mechanical engineering on the Lexington campus responsible for recommendations to university administration for the appointment of new faculty, promotions, re-appointments, and other faculty-related matters. The director is a member of the UK Mechanical Engineering Department and is involved in teaching in the Paducah program. Curricular and quality control of the 
programs is maintained by a blended faculty composed of both Paducah-based and Lexington-based UK faculty. The director is primarily responsible for staff hiring decisions in Paducah. The director participates in faculty hiring decisions, but faculty offers are made by the respective department chair, located on the Lexington campus. The organizational structure of the extended campus program in Paducah is depicted in Figure 2.

The extended campus programs in Paducah utilize a unique blend of faculty. The lower division courses are the responsibility of UK, MuSU, and PCC, with PCC fulfilling the traditional role with the liberal arts, mathematics, chemistry, and physics courses. MuSU and UK are responsible for the upper division courses. Administratively to accommodate this requirement, three MuSU faculty members have joint appointments to the UK mechanical engineering faculty. While the jointlyappointed MuSU faculty do not have voting privileges, they are consulted on all matters related to the Paducah program.

The mechanical engineering faculty on the Lexington campus formulated 4- and 5-year curricula for the program. The curricula are identical to the counterpart Lexington campus curricula, including the number of credits and all prerequisite requirements. The faculty insisted that first-year admission and upper-division admission (i.e., engineering standing) requirements be the same for the Paducah program as for the Lexington campus. Hence, engineering courses offered in Paducah are virtually the same as those in Lexington. Common course syllabi, examinations and grading scales are used to assure consistency of educational outcomes at both sites. Faculty in Lexington and in Paducah work together in teaching the same course at both sites. Use of distance learning and teleconferencing technologies complement on-site offerings. Thus, faculties in both Lexington and Paducah are unified with comparable curriculum. Criteria for admission to engineering, admission to engineering standing, prerequisite adherence, and graduation requirements are identical.

Because the programs are hosted by an institution without a 4-year degree program (PCC), all students in the program will be transfer applicants from other institutions, or at a minimum, will transfer a significant number of credits to UK. (An exception is a small number of students who begin at UKLexington and then transfer to UK-Paducah.) Most students will be transfers from PCC, or will enroll at PCC and UK (through distance learning programs) concurrently.

\section{B. Faculty and Professional Staff}

As mentioned previously, the extended campus mechanical engineering program in Paducah uses a faculty consisting of UK faculty and three jointly appointed MuSU faculty for the upper division course offerings. The projected UK faculty necessary to staff the mechanical engineering program has been estimated to be four, with one position filled by the program director. This number, supplemented by instruction through use of distance learning technology (especially compressed video) will be sufficient to offer all four years of the degree program on-site in Paducah.

All of the UK faculty positions, with the exception of the director, will be filled in a special-title series. These positions are primarily upper division nine-month teaching appointments. However, due to the nature of the Paducah program, these appointments involve additional assignments, including student recruitment from local high schools and the business community, undergraduate laboratory and computer software development, assistance with summer job placement for students, and professional 
development. The traditional responsibilities involving instruction, academic advisement, and university service also apply. Because of these unique responsibilities and the limited access to graduate students, the expectation for research productivity is less than for the faculty on the Lexington campus.

The program currently has two faculty members in mechanical engineering. Recruitment is underway for two additional faculty members. This will complete the projected staffing for the mechanical engineering program. In addition, there are prospective adjunct faculty and/or lecturers available in the region, with both the proper academic credentials and experience, as well industrial experience if instructors are needed on a short-term basis.

The program is now fully staffed with regard to support personnel. The program staff includes an office assistant, a laboratory manager, and a director of student services. The director of student services' responsibilities include interfacing on a regular basis with admissions officers and various other UK staff, such as staff at UK's distance learning programs, engineering student records, directors of undergraduate studies, and staff support in the Lexington-based engineering programs. In addition, the director of student services is actively involved in recruiting at local high schools and maintains close contact with pre-engineering advisors and recruiters at PCC.

C. Enrollment

Current mechanical engineering class enrollment is 55 students, with an estimated enrollment of 58 students for fall 2000, as illustrated in Figure 3. Five mechanical engineering students are on track for a May 2000 graduation. Four of these students have transferred from the Lexington campus. It is estimated that three mechanical engineering students will graduate in May 2001.

Classes have been arranged semester by semester so that the initial mechanical engineering students can graduate in a timely fashion. With the current enrollment levels, courses are now stabilizing to reflect Lexington course offerings.

The fall 2000 enrollment projection was determined by analysis of applicants in UK's distance learning programs since fall 1997 and consultation with the pre-engineering advisors and recruiters at PCC. This estimate is thought to be consistent with enrollment trends at PCC, the primary feeder institution, and with compiled program-interest data. It is forecasted that by 2003-04, enrollment will stabilize at between 50 and 70, with graduation rates of approximately 10 per year.

For reference, the well established ABET-accredited UK-Lexington mechanical engineering enrollment and BS degrees conferred are presented in Figure 4.

Because of the geographic separation of the two UK programs (255 miles from Lexington to Paducah) and the local stimulus for program creation, the programs in Paducah are not considered unnecessarily duplicative. Additionally, as the programs in the Purchase Region develop, innovative courses, programs, and delivery modes are envisioned. Development of the programs is consistent with the university's land-grant mission.

It is not anticipated that the extended campus programs will adversely affect enrollment in similar 
programs in Kentucky. In fact, the two new programs might even increase participation in engineering education through heightened awareness of engineering opportunities in the region. Furthermore, as reported in the MGT study ${ }^{1}$, while Kentucky high school seniors have a relatively typical interest in engineering as a college major, enrollment in engineering education in the Purchase Region, based on limited data, appears much lower. Establishment of engineering programs in Paducah should result in a marked increase in engineering enrollment among students from the Purchase Region due to increased awareness in engineering education.

\section{Resources}

\section{A. Facilities}

The extended campus programs on the PCC campus are housed in a new 53,000 square foot building with the College of Engineering assigned approximately $40 \%$ of the usable space. Besides office areas, student work areas, and classrooms, it also houses the computing and experimental laboratories. The building, Crounse Hall, was constructed on the PCC campus with locally generated funding from a capital campaign conducted by the Paducah Junior College Board, the local development and fundraising agent for PCC. The dedication of Crounse Hall was attended by approximately 500 local business and political leaders, staff and administration from the three participating institutions, and residents from throughout the Purchase Area region, which illustrates the level of commitment by the region for success of the programs.

\section{B. Library}

It was necessary to upgrade the PCC library to ensure the engineering programs in Paducah would have proper library resource availability. Acquisitions of reference books, journals, and handbooks, and the development of faculty and student library support services are on-going and are being handled by UK's CoE head librarian and by PCC's library director. The college purchased a facsimile machine for student use at PCC to receive journal articles from the archives of UK's College of Engineering Library. Compendex Index gratuitously extended UK's license for use by the extended campus engineering programs in Paducah.

Off-campus access to the UK collections is available through the website of the university library, where remote users can search the public catalog, as well as utilize the multiplicity of websites that have been pre-selected for their information value. The Shaver Engineering Library in Lexington also has an active website, which can be used by remote users to search databases and information sources identified specifically for the engineering disciplines. In addition, telefacsimile requests can be made to the interlibrary loan department for document delivery or inquiries can be made directly to the Shaver Engineering Library.

PCC presently holds 84 reference and circulating books acquired specifically to support the two new programs, in addition to a solid foundation of basic science and technology resources. The library also subscribes to several engineering journals in paper form and many more in electronic form. 


\section{Laboratory Facilities}

The computing facilities consist of a well equipped PC laboratory with over 20 high end PC's with a networked laser printer. The computers are networked to the PCC campus and UK-Lexington. All students have UK email addresses to receive university announcements and for course communication. They also have access to the Internet. The computers have complete software packages for report writing and engineering course work.

The philosophy used for experimental laboratory equipment has been to purchase off-the-shelf items. This allowed the Paducah program to provide a meaningful laboratory experience for students right from the start of the program. Some of the equipment includes a converging-diverging nozzle, various types of heat exchanges, fluid flow apparatus, low speed wind tunnel, and turbojet test facility. The purchase of this equipment was from a $\$ 1.1 \mathrm{M}$ start-up equipment allocation appropriated by the state over a two year period.

\section{Distance Learning}

The Commonwealth of Kentucky has invested heavily in distance learning infrastructure within the last decade. Initial plans were to use the system to deliver graduate-level instruction to parts of the state that were distant from the major research institutions. One of the first compressed video (CV) links to the University of Kentucky campus in Lexington was from Paducah Community College. This link was established to satisfy an expressed need for graduate engineering and education courses. Graduate level courses have been offered in both masters and doctoral degree programs. A class of about 30 students recently completed their EdD degree programs through the use of $\mathrm{CV}$ for all coursework. There are currently more than a dozen community colleges and regional universities connected with the University of Kentucky CV system. The entire Kentucky Telelinking Network has approximately 140 fully equipped interactive video rooms.

As an extension of the engineering programs on the UK campus in Lexington, it was obvious that the use of CV would be instrumental, especially in the early development of the Paducah programs. The first engineering courses were taught in Paducah via CV, originating from Lexington and from MuSU. There are typically 2 to 4 courses transmitted by CV each semester between the Lexington and Paducah campuses, with courses originating at each location. These courses have proven invaluable to the Paducah programs as on-site faculty members are hired. The availability of the CV courses from Lexington has permitted the first upper-level students in the program to progress at their scheduled pace even when a faculty member with a particular specialization had not yet been hired in Paducah. This linkage has also permitted the areas of specialization of the new faculty members in Paducah to complement the areas of the faculty in Lexington. For example, one jointly appointed MuSU faculty member with a specialization in basic manufacturing methods now regularly teaches an introductory manufacturing class via CV from Paducah to Lexington. His availability has permitted the ME department to fill a recently vacated position with a faculty member having a more specialized manufacturing background. In addition, one new ME faculty member at Paducah with about 10 years of industrial experience in aircraft engine development has offered a dual level (senior-M.S.) course in turbomachinery via CV, one which had never before been offered in Lexington. 
There are obviously some problems to overcome with this application of compressed video, as with any new technology. One important issue is the availability of a knowledgeable facilitator at remote sites to provide help with homework and course questions. While the instructors are encouraged to provide several of their lectures from the remote site, it is difficult to provide the same level of course support at both sites that would be needed prior to examinations and major project due dates. Graduate students will provide CV course facilitation in Lexington, while the Paducah-based faculty members and post docs will facilitate courses in Paducah.

Distance learning courses have been received by the students with mixed results. Just as in live classroom instruction, there are varying degrees of instructor effectiveness. However, a CV course has the potential to let the technology interfere with effective course delivery. The instructors can control all three cameras at each location, as well as being able to show computer generated images and videotapes. While the multimedia possibilities are necessary to provide a range of instructional activities, most courses are still centered around the traditional lecture format. Switching cameras between the instructor and the text images requires a constant mental effort. Students in a small $(<10)$ $\mathrm{CV}$ class also lose the potential for anonymity that is possible by sitting in the back of a larger class. While this should be viewed positively, some students are somewhat uncomfortable "being on camera" where they think the instructor or the students at the other site may scrutinize their actions or appearance. Student evaluations have indicated little difference in how a CV course is received between the live class and the remote class. We are continuing to evaluate the differences between a $\mathrm{CV}$ class and a conventional live class in terms of student outcomes and overall course effectiveness.

As the full complement of on-site faculty is hired at Paducah, there will be less dependence on distance learning for required courses. Several courses, such as introductory manufacturing, lend themselves to this method of delivery when complemented with lecture notes and materials made available on the Internet. These courses will likely be continued as CV offerings, along with somewhat unique technical electives that may originate from either location. The plan for the long term is to focus on a relatively small number of required courses for delivery by distance learning technology, permitting limited resources to be targeted toward upgrading courses already well taught with these media.

Figure 5 presents the evolution of mechanical engineering classes for the Paducah program. As illustrated, the number of classes are increasing with the percentage of $\mathrm{CV}$ classes originating from Lexington decreasing as more faculty join the Paducah program. Additionally, CV courses originating in Paducah are depicted showing that areas of specialization of the faculty members in Paducah are being utilized to complement the areas of the faculty in Lexington

\section{Comparative Programs}

The extended campus programs are unique in that they are located on a community college campus and are the direct responsibility of a main campus dean of a four-year institution.

Within Kentucky there are no comparable programs to the UK-Paducah extended campus program. Mechanical engineering programs are offered at the University of Louisville and UK-Lexington, which are both four-year universities and located more than 200 miles away from the Purchase Area. 
The closest known example in the U.S. is the branch campus of Washington State University in Richland, WA. This "Tri-Cities" campus is approximately 156 miles from the Pullman campus and offers undergraduate degrees in mechanical engineering, electrical engineering, and computer science. In addition, a B.S. program in manufacturing engineering, to be administered by the WSU School of Mechanical and Materials Engineering, is currently under development for the Vancouver Campus. Similarities with the programs in Paducah include the following: approximately the same number of resident faculty; planned use of distance learning technologies (to the appropriate level); distinct accreditation action sought; one dean and chairperson per program (located on main campus). Major differences from the Paducah program exist in that WSU employs a campus dean at each of the branch campuses; by design, branch campuses can teach only upper-division courses; there is a split financial system, such that the department chair and academic dean (Pullman) have programmatic responsibility but little/no financial control; and branch campuses have selected (and limited) M.S. degree production.

Enrollment and graduation data for the branch campus of Washington State University, Richland ${ }^{2}$ are presented in Figure 6 for the mechanical engineering program along with the comparable data for the UK-Paducah program.

\section{ABET Accreditation}

Since the mechanical engineering program at Paducah is distinct from its Lexington counterpart in terms of location, facilities, administration, and support services, the program will seek distinct ABET accreditation (a decision not made unilaterally by the institution but determined ultimately by the accreditation agency). With the goal of achieving accreditation status at the earliest opportunity, college task forces have been working with ABET-EAC staff and ABET-knowledgeable consultants to ensure that program development is progressing toward this goal. The Paducah program recently held an ABET Planning Committee Meeting, which was attended by representatives of all three participating institutions to initiate work toward the goal of ABET accreditation.

Current program objectives are similar to those on the Lexington campus and have been reviewed by the department faculty. However, these objectives will be reviewed periodically with modifications made, as appropriate, as the program evolves. The objectives, of course, will be based on the ongoing practice of' continuous improvement, which includes formal collection of input from constituencies.

UK engineering programs were evaluated under the new ABET Engineering Criteria 2000 in November 1998. In August 1999, the college was informed by the EAC that all of the undergraduate programs in the College have been re-accredited. If the Paducah programs are accredited distinctly, an accreditation visit could be requested for the new program soon after there is a sufficient amount of data from graduates and other stakeholders.

\section{Summary}

The University of Kentucky is using an extended campus concept to develop new programs in 
mechanical and chemical engineering in western Kentucky to provide engineering graduates as well as further engineering educational opportunities for local industries in the area. The programs are located on the Paducah Community College campus, which is 255 miles from the Lexington campus. Based on Kentucky legislation three institutions are involved in the Paducah programs (University of Kentucky, Murray State University, and Paducah Community College) with the University of Kentucky being the degree-granting institution.

The extended campus programs are unique in the following areas:

1) the programs are resident on a community college campus;

2) the dean of the University of Kentucky College of Engineering in Lexington is responsible for administration;

3) an integrated faculty from three institutions serve as the resident faculty;

4) resident University of Kentucky faculty are appointed in a special-title series; and

5) distance learning (where appropriate) will remain part of the program.

The programs started in the summer of 1997 with 5 students ( 4 in mechanical engineering). This fall semester (1999) there are 55 students enrolled in the mechanical engineering program (an additional 12 students are in the sophomore pre-requisite curriculum). Five mechanical engineering students are on-track to graduate in May 2000, with three more students estimated to graduate in May 2001.

The basic infrastructure has been established (engineering and science building, library resources, laboratories, and staff) to ensure a successful program.

Since the mechanical engineering program at Paducah is distinct from the Lexington campus, the program will seek separate ABET accreditation. Accreditation, of course, will follow the new ABET Engineering Criteria 2000. Experience gained during the college's 1998 visit under Criteria 2000 should be of significant value, especially since the programs in Paducah are administered by the same chairs as the programs in Lexington.

Bibliography

1. MGT of America, Inc., "Engineering Education Needs and Instructional Delivery Models for Far Western Kentucky,” (1995).

2. Personnel communication from Denny C. Davis, Associate Dean for Undergraduate Programs and Student Services, Washington State University (June 1998). 


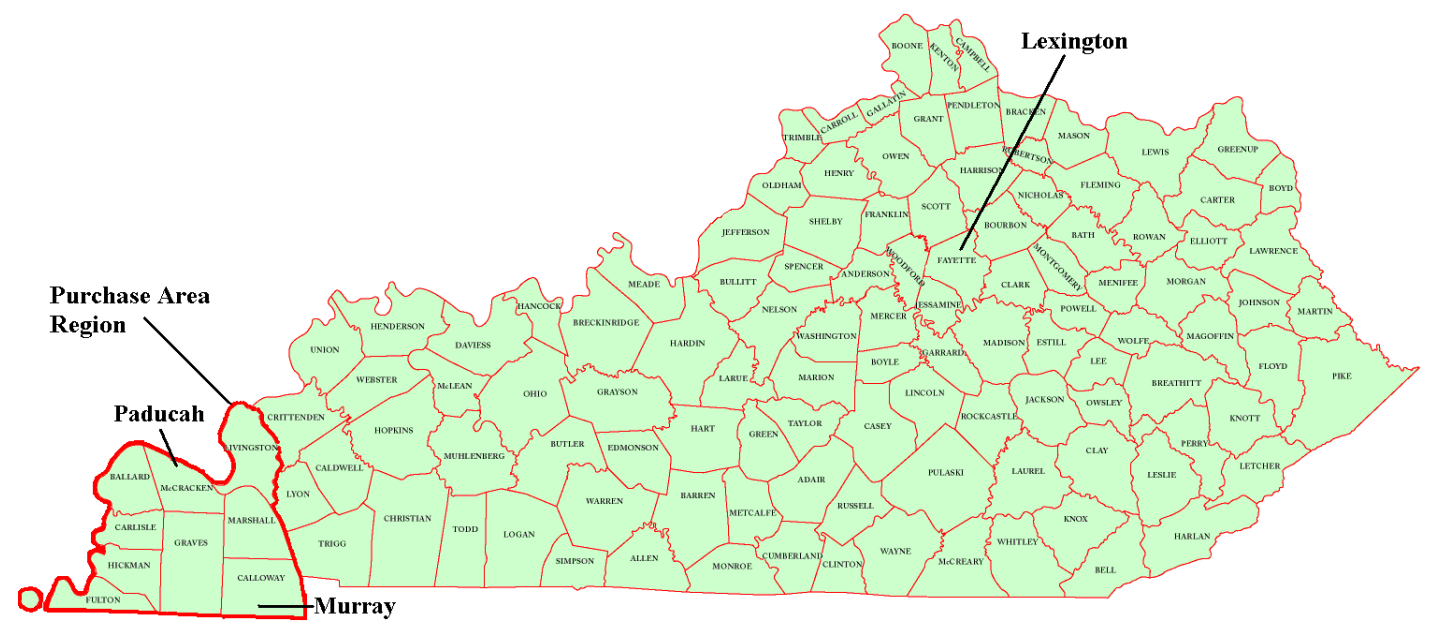

Figure 1. Map of the Commonwealth of Kentucky.

\section{ORGANIZATIONAL CHART}

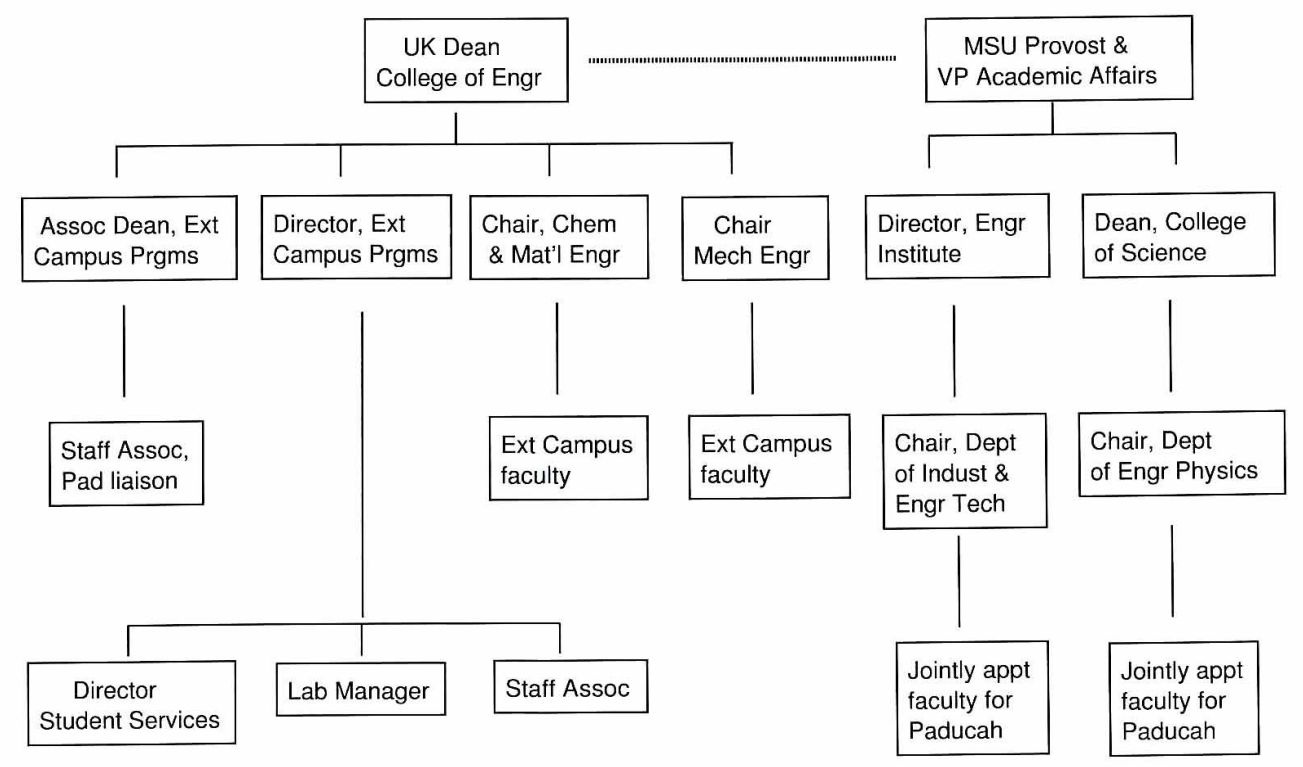

Figure 2. The organizational chart for the extended campus programs in Paducah 


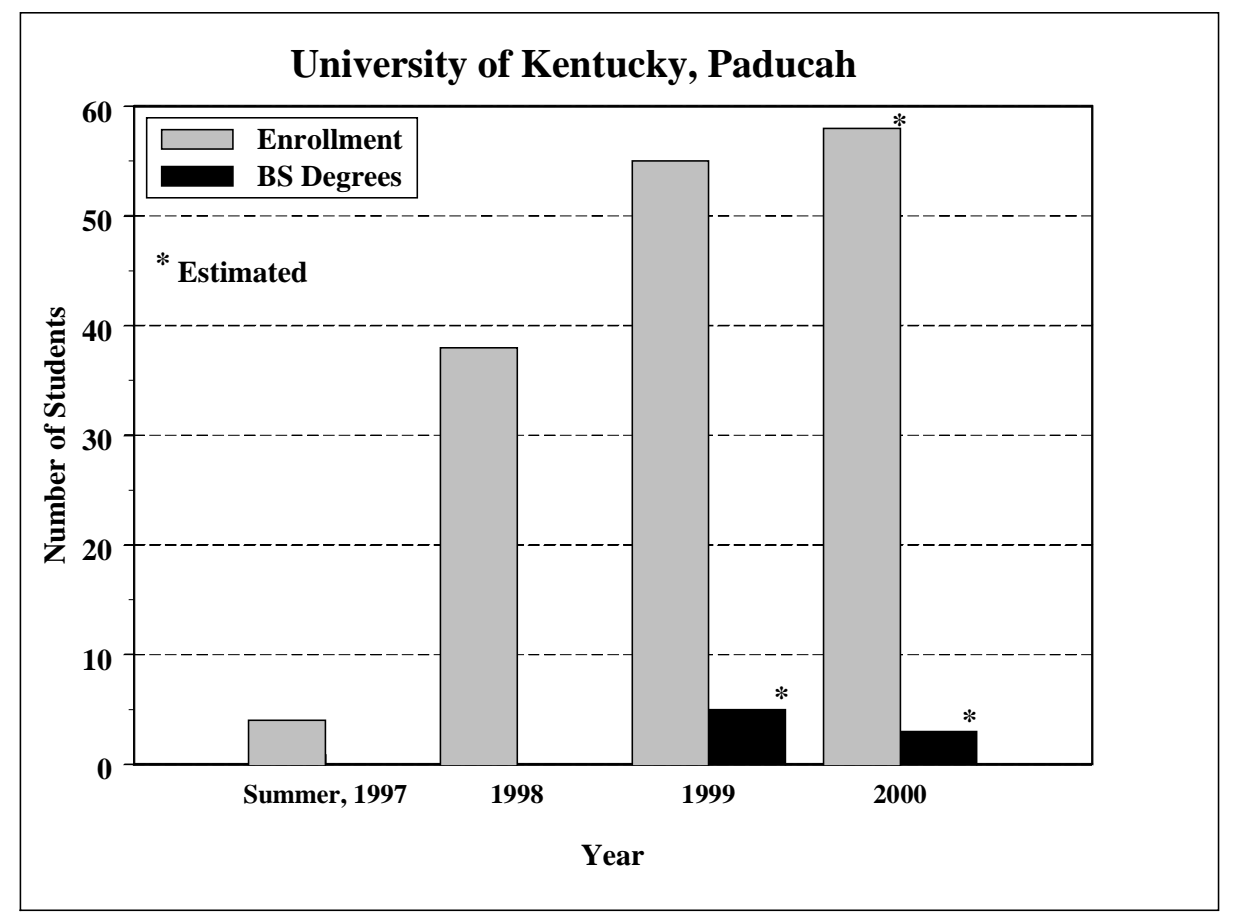

Figure 3. Enrollment and estimated B.S. degrees for the Paducah extended campus mechanical engineering program.

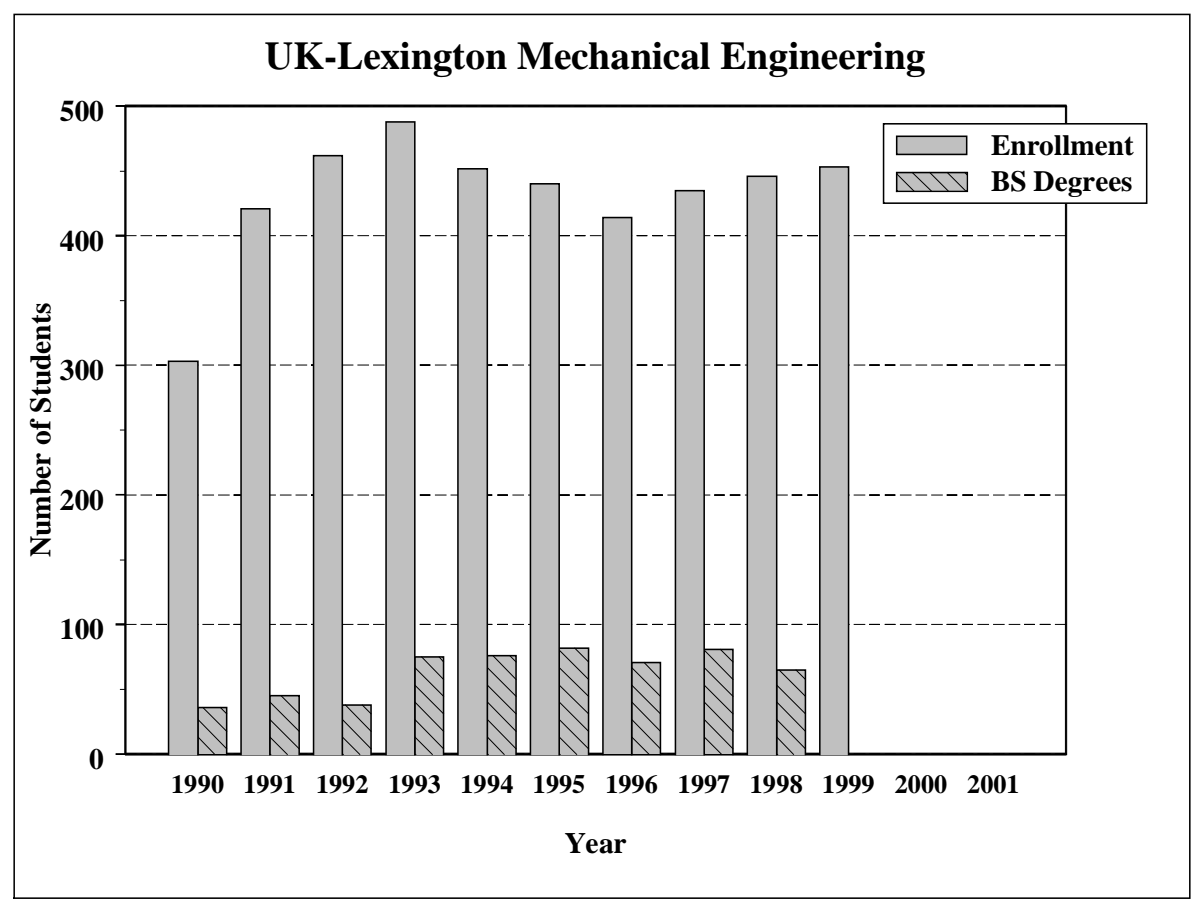

Figure 4. Enrollment and B.S. degrees for the Lexington mechanical engineering program. 


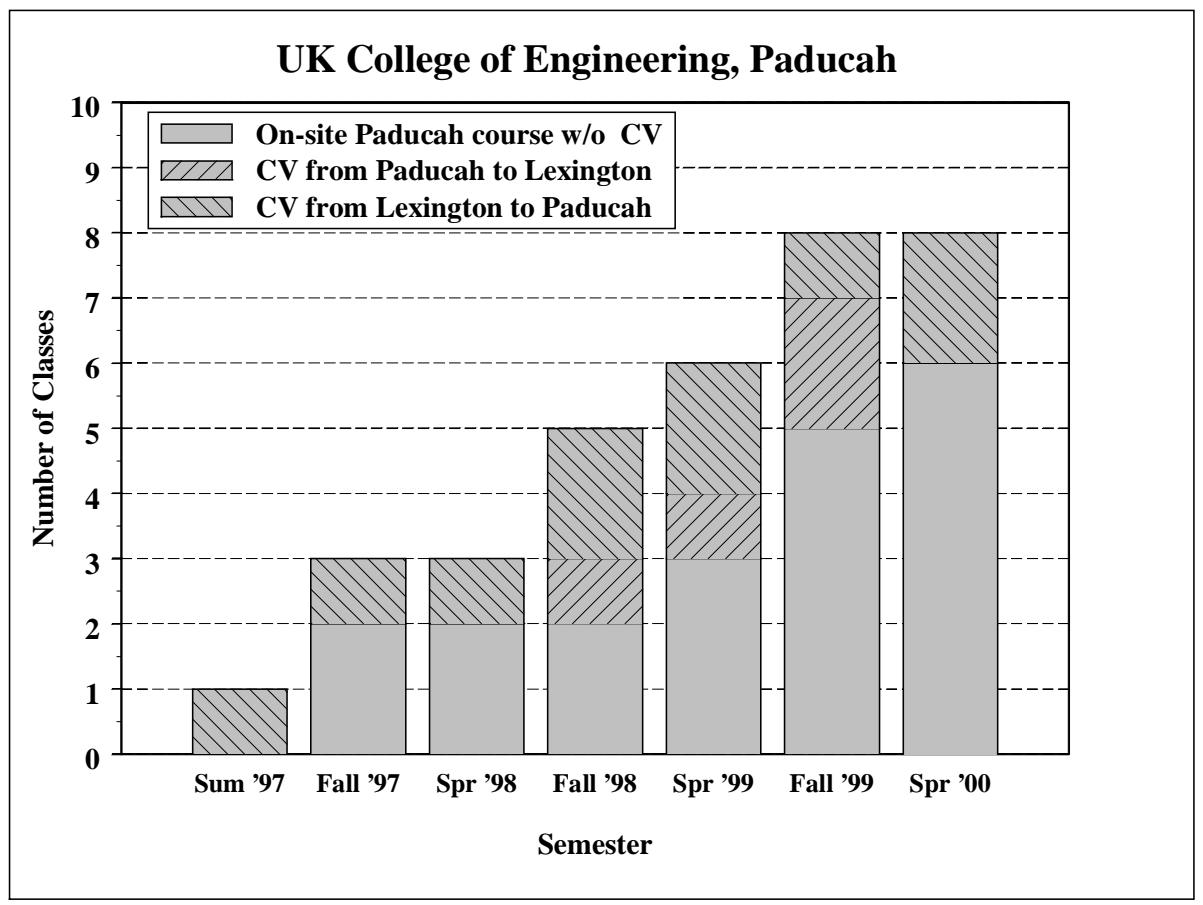

Figure 5. Number of mechanical engineering classes at UK-Paducah including the number of classes offered with the compressed video (CV) distance learning technology.

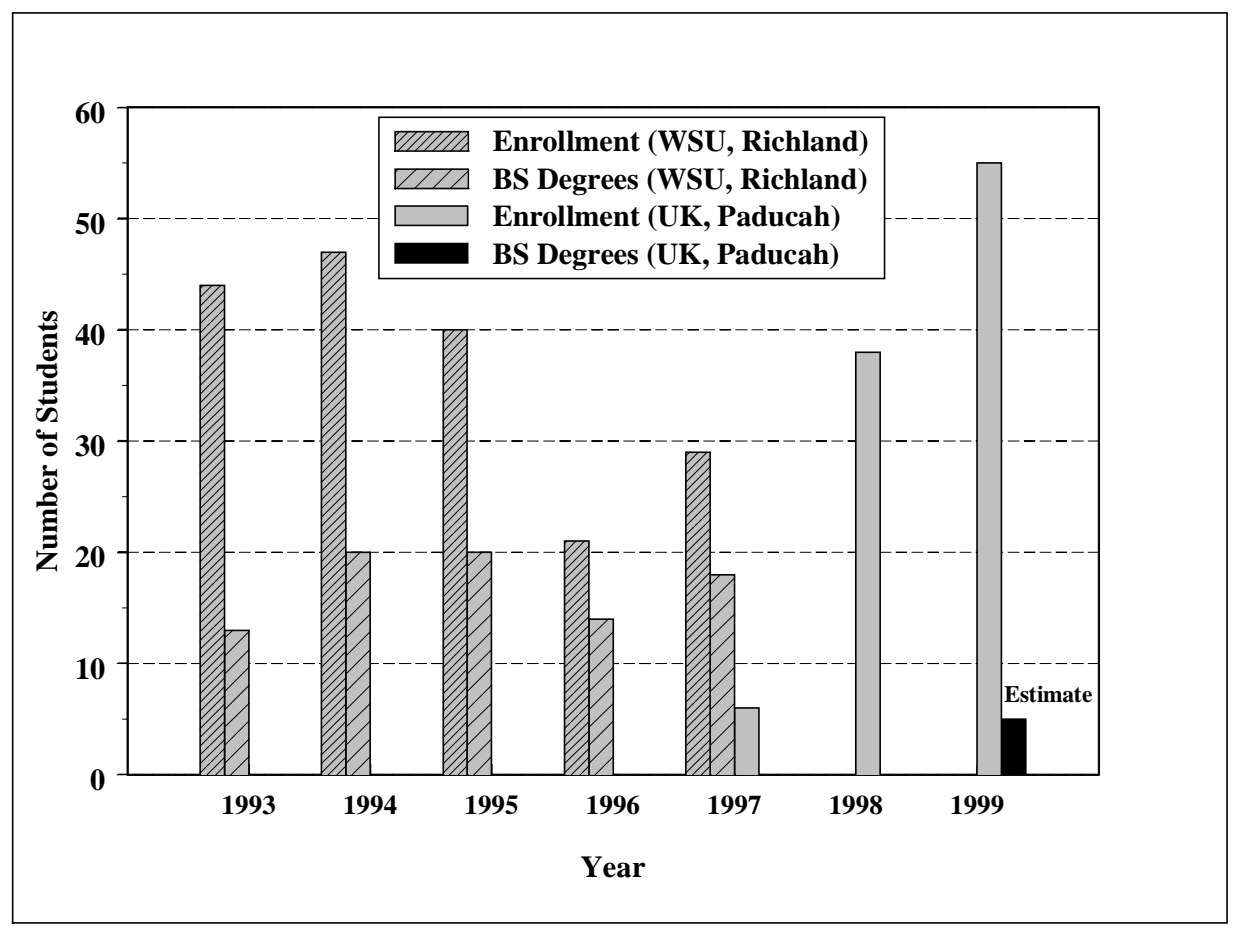

Figure 6. Comparison of the enrollment and degrees granted for Washington State University, Richland and UK-Paducah. 


\section{VINCENT R. CAPECE}

Vincent R. Capece is an Assistant Professor of Mechanical Engineering. Dr. Capece received his B.S. degree in Mechanical Engineering from Tennessee Technological University in 1980, M.S. in Mechanical Engineering from MIT in 1982, and Ph.D. from Purdue University in 1987.

\section{WILLIAM E. MURPHY}

William E. Murphy is a Professor of Mechanical Engineering with the University of Kentucky and Director of the Engineering Extended Campus Programs in Paducah. Dr. Murphy received his B.S. degree from the University of Kentucky and his M. S. and Ph.D. degrees from Purdue University, all in Mechanical Engineering. He is a member of the ABET EAC and a past ABET Director representing ASHRAE. He is a licensed Professional Engineer in Kentucky.

\section{G.T. LINEBERRY}

G.T. Lineberry is Associate Dean for Extended Campus Programs and Professor of Mining Engineering with the University of Kentucky. Dr. Lineberry received his BS and MS degrees from Virginia Tech and his PhD degree from West Virginia University, all in Mining Engineering. He is author/coauthor of over 60 journal articles, conference proceedings, and book chapters, and was a section coordinator and contributor to the SME Mining Engineering Handbook (2nd ed).

\section{BONITA LYKINS}

Bonita Lykins is director of student services for the UK College of Engineering, Extended Campus Programs in Paducah. Lykins completed her B.A. degree in English and History in 1966, her M.A.Ed. degree in 1975, and additional post graduate work in educational administration at Murray State University, Murray, Kentucky. 